\title{
Thiram - Toxic inhalational lung injury
}

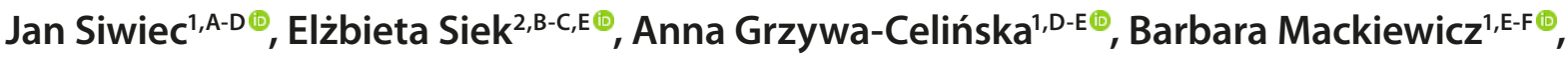 \\ Elżbieta Czekajska-Chehab ${ }^{2, E-F \oplus ~}$
}

\author{
${ }^{1}$ Chair and Department of Pneumonology, Oncology and Allergology, Medical University, Lublin, Poland \\ 2 1st Department of Medical Radiology, Medical University, Lublin, Poland \\ A - Research concept and design, B - Collection and/or assembly of data, C - Data analysis and interpretation, \\ $D$ - Writing the article, E - Critical revision of the article, F - Final approval of article
}

\begin{abstract}
Siwiec J, Siek E, Grzywa-Celińska A, Mackiewicz B, Czekajska-Chehab E. Thiram - Toxic inhalational lung injury. Ann Agric Environ Med. 2019;
\end{abstract} 26(4): 672-673. doi: 10.26444/aaem/110469

\begin{abstract}
I Abstract
Introduction. Thiram, a fungicides, is widely used on seeds and as foliar agent on turf, vegetables and fruit. It is also used in the rubber industry as a vulcanization accelerator. When absorbed through the respiratory system, it is rapidly metabolised to dimethylthiocarbamate and carbon disulphide, causing noxious effects. A brief review is presented of the literature, centering on the interesting case of a 45-year-old woman admitted to the hospital suffering from acute respiratory failure. Results. Computer tomography in angiographic option (angio-CT) showed an extensive, irregular area of ground glass in both upper lobes and apical segments of the lower lobes of the lungs. A significant enlargement of both atria was also described. There was no improvement after cardiac treatment and patient was transferred to the pulmonary department where she was succesfully treated with systemic glucocortycosteroids. The patient remains under the supervision of the pulmonary out-patient department.
\end{abstract}

\section{Key words}

thiram, lung injury, inhalation

\section{CASE DESCRIPTION}

A 45-year-old woman was admitted to hospital due to acute respiratory failure, without fever. The clinical picture suggested pulmonary oedema. In relation to clinical features and suspicion of pulmonary embolism, computer tomography in angiographic option (angio-CT) was performed. Computed tomography (CT) examination ruled out pulmonary embolism. Nevertheless, extensive, irregular areas of ground glass were found in both upper lobes and apical segments of lower lobes of the lungs. Those findings tended to formulate the perihilar consolidations. Relative sparing of peripheral zone was observed [Fig.1a, 1b]. Small areas of lung consolidation and athelectasis were also observe in the basal segments of both lungs. These lesions were associated with thickening of interlobular sept in the lower lobes of both lungs and the hydrothorax. A noticeable enlargement of both atria was also described [Fig. 1c]. There was no improvement after first-step cardiac treatment. The patient was referred to the lung disease department. The medial history indicated an acute interstitial lung disease due to inhalation of an antifungal substance - thiram. Dyspnoea appeared within an hour after exposure. After receiving $250 \mathrm{mg}$ of metylopredisolone pulses a significant improvement in the general condition was observed, together with relief of dyspnea, crackles and radiological changes. In peripheral blood tests, bronchoalveolar lavage and transbronchial lung biopsy, connective tissue diseases and chronic lung diseases were excluded. After ten days of treatment, complete resolution of the upper and midlung zones and hydrothoax was found in high resolution

Address for correspondence: Anna Grzywa-Celińska, Chair and Department of Pneumonology, Oncology and Allergology, Medical University, Lublin, Jaczewskiego 8, 20-954, Lublin, Poland

E-mail: acelin@op.pl

Received: 23.05.2019; accepted: 29.06.2019; first published: 18.07.2019 computed tomography (HRCT) [Fig.1.d,e]. In the lateral basal segment of the right lung, a new, small, peripheral area of consolidation appeared. On the CT scans, all heart chambers were normal size [Fig.1f].

\section{DISCUSSION}

Thiram belonging to dithiocarbamate group (tetramethylthiuram disulfide) of fungicides, widely used on seeds and as foliar agent on turf, vegetables and fruit [1]. It is also used in the rubber industry as a vulcanization accelerator, in the production of plastics, paints, varnishes, dressings and aseptic soaps [1]. Thiram is easily absorbed through the respiratory system and is rapidly metabolised to

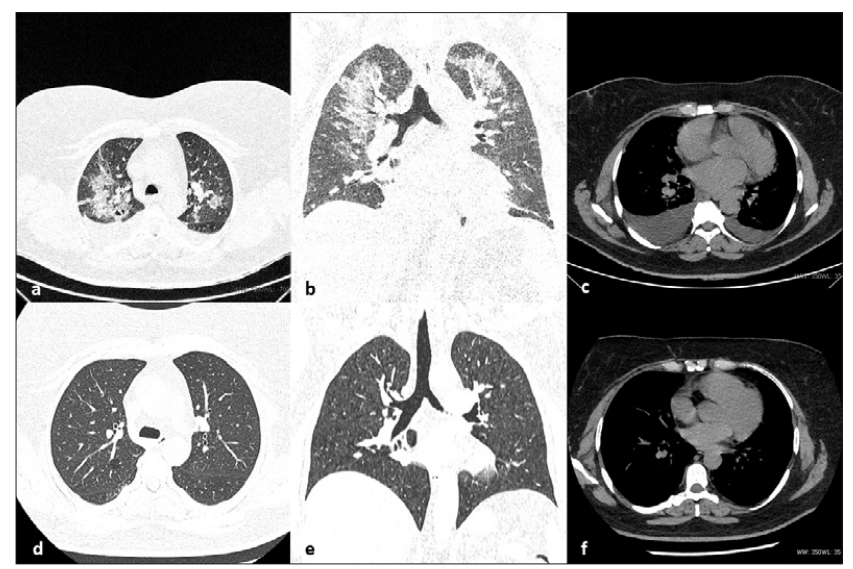

Figure 1. Computed tomography (CT) imaging of the chest in acute phase of the disease. A. Axial imaging. Patchy, irregular area of ground glass in both upper lobes of the lungs with tendency to consolitation. Relative sparing of peripheral zone. B. Coronal plain in acute phase. Area of ground glass and consolidation in upper and mid zones of both lungs, mainly perihilar. C. On axial plain hydrothorax bilaterally and increasing of volume of left atrium of the heart. D, E, F. Resolution of features in control examination. 
dimethylthiocarbamate and carbon disulphide, which cause toxic effects [1]. Thiram and its derivatives chelate metals and inhibit enzymes by interfering with the metabolism of carbohydrates, alcohols, dopamine and calcium, damaging cell membranes. Thiram is the third most common allergen found in occupational circumstances [2]. There is a small number of reports of the toxic effects of thiram in humans. The symptoms of acute exposure mostly include headaches, vomiting, arrhythmia, mucous membranes irritation and bronchitis. Neurological disorders, skin changes, and liver injury may occur with long-term exposure [1]. No cardiotoxic activity was found in laboratory tests. Carbamate pesticides induced significant apoptosis in human natural killer cells [3]. Thiram induced apoptosis in human T cells, and the apoptosis is mediated by the activation of caspases and the release of mitochondrial cytochrome-c [3]. Thiram leads to oxidative cellular damage, as reflected by increased lipid peroxidation, and finally, loss of cell viability [4]. Inhalation of thiram causes much more acute poisoning than any other route of exposure. Only one case reporting an acute and lethal toxic pneumonia after inhalation of thiram has been found [1]. In the presented case, because of the misleading clinical picture, the most important role in establishing the proper diagnosis was played by proficient history-taking and good cooperation between the clinician and the radiologist.

\section{Acknowledgements}

The authors thank dr Maciej Siczek of the Radiology Department, Hospital of the Ministry of Internal Affairs and Administration in Lublin, Poland, for assistance and comments that greatly improved the manuscript.

\section{REFERENCES}

1. Struciński P. Tiuram - pyły [Thiram - dusts]. Podstawy i Metody Oceny Środowiska Pracy. 2006; 3: 145-180. [polish]

2. Arrandale VH, Liss GM, Tarlo SM, Pratt MD, Sasseville D, Kudla I et al. Occupational Contact Allergens: Are They Also Associated With Occupational Asthma? Am J Ind Med. 2012; 55: 353-360.

3. Li Q, Kobayashi M, Kawada T. Carbamate Pesticide-Induced Apoptosis in Human T Lymphocytes. Int J Environ Res Public Health. 2015; 12: 3633-3645.

4. Cereser C, Boget S, Parvaz P, Revol A. Thiram-induced cytotoxicity is accompanied by a rapid and drastic oxidation of reduced glutathione with consecutive lipid peroxidation and cell death. Toxicology. 2001; 163: 153-162.

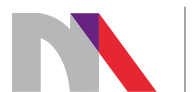

Ministry of Science and Higher Education

Republic of Poland

Generation of the DOI (Digital Object Identifier) - task financed under the agreement No. 618/P-DUN/2019 by the Minister of Science and Higher Education 